Nataša Vidić ${ }^{1}$, Aleksandar Đenić ${ }^{2}$

\title{
INHIBITOR NATRIJUM-GLUKOZNOG KOTRANSPORTERA TIPA 2 - DAPAGLIFLOZIN U TERAPIJI OBOLELIH OD DIABETES MELLITUS TIPA 2
}

Sažetak: Dapagliflozin je visoko selektivni inhibitor natrijum-glukoznog kotransportera tipa 2 - SGLT2i (engl. sodium/glucose cotransporter 2 inhibitor), koji je odobren za tretman obolelih od DM tipa 2, kao monoterapija ili u kombinaciji sa drugim preparatima. U poređenju sa placebom grupe kojima je ordiniran dapagliflozin, pokazale su značajniji pad HbA1c: -0,58\% (dapagliflozin 2,5mg), $-0,77 \%$ (dapagliflozin $5 \mathrm{mg}$ ) i -0,89\% (dapagliflozin $10 \mathrm{mg}$ ) u odnosu na grupu koja je primala placebo $(0,23 \%)$. Gubitak telesne mase povezan sa upotrebom SGLT2 inhibitora održava se tokom kliničkih studija do 104 nedelje. Upotreba ovih lekova je povezana sa redukcijom i mortaliteta i morbiditeta od kardiovaskularnih oboljenja. Indirektno renoprotektivno dejstvo SGLT2i se ostvaruje smanjenjem bubrežne resorpcije glukoze i smanjenjem koncetracije glukoze u krvi, uz redukciju telesne mase i indeksa telesne mase. Genitalne infekcije su najčešća nuspojava dapagliflozina i ne savetuje se upotreba ovog leka kod pacijenata sa aktivnim karcinomom mokraćne bešike i treba ga propisati oprezno kod osoba sa istorijom karcinoma mokraćne bešike i nerazjašnjenom hematurijom. S obzirom na dobru toleranciju leka, lako doziranje i minimalni rizik od neželjenih efekata, osim genitourinarnih infekcija, dapagliflozin, kao i drugi lekovi iz ove grupe adekvatan su izbor kod pacijenata obolelih od DM2, posebno onih sa visokim kardiovaskularnim rizikom.

Ključne reči: dapagliflozin, SGLT2i, diabetes mellitus tip2, kardiovaskularni rizik, genitourinarne infekcije

$1 \quad$ Nataša Vidić, Zdravstveni centar Užice, natasa.neskovic977@gmail. com

2 Aleksandar Đenić, Specijalna bolnica za bolesti štitaste žlezde i bolesti metabolizma Zlatibor, djenic.cigota@gmail.com 


\section{Uvod}

DM (lat. diabetes mellitus, DM) je jedno od najčešćih hroničnih, nezaraznih oboljenja, koje se karakteriše hiperglikemijom i pojavom brojnih mikro i makrovaskularnih komplikacija. (1) Uprkos velikom broju obolelih, preko 415.000 .000 odraslih osoba i različitim terapijskim opcijama optimalnu kontrolu glikemije postigne svega oko $50 \%$ obolelih, a broj onih koji postigne sve terapijske ciljeve (optimalnu kontrolu glikemije, holesterola i vrednosti arterijskog krvnog pritiska) iznosi oko $20 \%$. $(2,3)$

Ralph DeFronzo 2010. formuliše koncept „ominous octet” koji naglašava interakciju brojnih patofizioloških procesa u nastanku DM. (4) Srž patofiziološkog procesa čini disfunkcija $\beta$-ćelije uz IR (engl. insulin resistance, IR) na periferiji (skeletni mišići) i pojačanu produkciju glukoze na nivou jetre, povećanu lipolizu u prisustvu gojaznosti, ali i disfunkciju neurotransmitera centralnog nervnog sistema i poremećaj sekrecije inkretina i glukagona. $(5,6,7,8,9,10)$ Bubreg ima višestruki značaj za održavanje homeostaze glukoze. (11) Najznačajniji uticaj bubrega na homeostazu glukoze odigrava se kroz njenu resorpciju na nivou tubula, gde se normalno filtrira oko 1801 plazme i oko 180 gr glukoze za $24 \mathrm{~h}$, te da kod zdravih osoba skoro da nema glukoze u urinu, sve se resorbuje preko glukoznog transportera - SGLT. (12) Oko 90\% glukoze resorbuje se preko SGLT2, koji imaju visok kapacitet, ali nizak afinitet, a preostalih 10\% se resorbuje preko SGLT1, visokog afiniteta i niskog kapaciteta. $(13,14,15)$ Količina glukoze koja se filtrira kroz bubrege linearno se povećava sa povećanjem, plazmatske koncentracije glukoze, i smanjuje, sa smanjenjem glomerularne filtracije. (11) Odstupanje od ovog linearnog odnosa nastaje kada se prevaziđe resorptivni kapacitet i kada SGLT dostigne svoj transportni kapacitet. TmG (engl. tubular maximum glucose reabsorptive capacity, TmG) iznosi oko $375 \mathrm{mg} / \mathrm{min}$. (16) Ovo predstavlja i bubrežni prag za resorpciju glukoze, i nastaje pri koncentracijama glukoze preko $11,0 \mathrm{mmol} / \mathrm{L}$ kod zdravih odraslih osoba. (16) Kod obolelih od DM2 ovaj prag je viši, za oko 2,2 $\mathrm{mmol} / \mathrm{L}$, što kod osobe sa normalnom GFR (engl. glomerular filtration rate, GFR) i hiperglikemijom vodi dodatnom opterećenju glukozom oko 2,78-3,89 mmol/L. (11, $17,18)$ Kada plazmatska koncentracija glukoze raste iznad $11,0 \mathrm{mmol} / \mathrm{L}$ procenat filtrovane glukoze koja se resorbuje pada, a koncentracija glukoze u urinu raste. (12)

\section{SGLT2 inhibitori u fokusu}

Dapagliflozin je visoko selektivni inhibitor natrijum-glukoznog kotransportera tipa 2 - SGLT2i (engl. sodium/glucose cotransporter 2 inhibitor, SGLT2i), koji je odobren za tretman samo obolelih od DM tipa 2, kao monoterapija ili u kombinaciji sa drugim preparatima. (19) Smanjenjem kapaciteta za tubularnu resorpciju glukoze i smanjenjem renalnog tubularnog gradijenta za pojavu glukoze u urinu, upotreba dapagliflozina rezultuje povećanjem izlučivanja glukoze preko bubrega i kod zdravih 
volontera i kod obolelih od DM. (20) Urinarni gubici su proporcionalni koncentraciji glukoze, i samim tim je veći gubitak kod osoba sa većom serumskom koncentracijom glukoze. Sa prosečnom dnevnom dozom dapagliflozina povećava se eliminacija glukoze urinom za oko 50-80 g/dan, što uslovljava pad koncentracije glukoze u plazmi i posledično poboljšanje parametara glikoregulacije. $(11,21,22)$ Povećanje glikozurije počinje se sa prvom dozom i održava se tokom hroničnog tretmana najmanje dve godine. (20, 23) Ovaj mehanizam je nezavisan od delovanja insulina. (24) Zbog toga je rizik od hipoglikemija minimalan i ne postoji opasnost od prekomerne stimulacije $\beta$-ćelija. (25)

Pozitivni efekti ove grupe lekova se objašnjavaju: smanjenjem stresa $\beta$-ćelije, smanjenjem hiperinsulinemije i povećanjem insulinske senzitivnosti, usled restrikcije kalorijskog opterećenja i posledičnog gubitka telesne mase; povećanjem koncetracije „supergoriva” za tkivo, pre svega miokarda, promovišući adaptivnu ketogenezu. Upotreba SGLT2i praćena je smanjenjem lučenja insulina i blagim povećanjem nivoa glukagona. Promenom ovog odnosa povećava se iskorišćavanje lipida. Oslobođene slobodne masne kiseline se metabolišu do ketonskih tela kao odgovor na glukagon i bivaju preuzete od strane miokarda. Ketonska tela povećavaju efikasnost miokarda bez povećanja oksigenacije, uz rizik da se ova nežna ravnoteža lako može narušiti u slučaju gladovanja, posta, trudnoće, što može usloviti razvoj ketoze. Ovim povećanjem efikasnosti miokarda dolazi do popravljanja oksigenacije perifernih tkiva usled porasta hematokrita, a bez povećanja srčane frekvence. (26)

\section{Klinička efikasnost dapagliflozina}

SGLT2 inhibitori imaju mehanizam dejstva koji je potpuno nezavisan od funkcije $\beta$-ćelija Langerhansovih ostrvca, tako da je moguća kombinacija ovih preparata sa svim drugim terapijskim opcijama. $(24,27)$ Značajan pad HbA1c je viđen u mnogim studijama bilo da se lek primenjuje kao mono ili kombinovana terapija.

Ferrannini je sa saradnicima pokazao efikasnost dapagliflozina u monoterapiji DM2. U toj studiji ispitanici (oboleli koji nisu postigli adekvatnu glikoregulaciju sprovođenjem higijensko-dijetetskog režima) su randomizovani u četiri grupe (placebo, dapagliflozin $2,5 \mathrm{mg}, 5 \mathrm{mg}$ i $10 \mathrm{mg}$ ). U poređenju sa placebom grupe kojima je ordiniran dapagliflozin, pokazale su značajniji pad HbA1c: - $0,58 \%$ (dapagliflozin 2,5 $\mathrm{mg}$ ), $-0,77 \%$ (dapagliflozin $5 \mathrm{mg}$ ) i $-0,89 \%$ (dapagliflozin $10 \mathrm{mg}$ ) u odnosu na grupu koja je primala placebo $(0,23 \%)$. Tokom 24 nedelje, koliko je trajala studija, zapažena je redukcija glikemije našte od $1,11 \mathrm{mmol} / \mathrm{L}$ i $1,39 \mathrm{mmol} / \mathrm{L}$ sa dapagliflozinom od $5 \mathrm{mg}$, odnosno $10 \mathrm{mg}$ i to već nakon prve nedelje lečenja. Efekat terapije je takođe bio bolji u grupi pacijenata koji su na početku ispitivanja imali viši nivo HbAlc. (28) Slične rezultate su prikazali Bailey i saradnici: pacijenti na terapiji sa dapagliflozinom su uz prosečno veću redukciju glikemije našte imali i značajnu redukciju telesne 
mase. (29) Pozitivan efekat primene dapagliflozina pokazan je i u kraćim studijama u kojima su se poredili efekti metformina produženog dejstva, dapagliflozina i placeba. Već u 12. nedelji istraživanja kod svih pacijenata sa dapagliflozinom postignuta je značajna redukcija $\mathrm{HbA} 1 \mathrm{c}(-0,55 \%$ do $-0,90 \%)$, a redukcija glikemije našte tokom prve nedelje (iznosila je od $0,89 \mathrm{mmol} / \mathrm{L}$ do $1,72 \mathrm{mmol} / \mathrm{L}$ ) koja je dozno zavisna. (30) $\mathrm{Na}$ kraju 12. nedelje 59\% pacijenata na terapiji dapagliflozinom, $54 \%$ pacijenata na terapiji metforminom postiglo je optimalni nivo HbA1c. (30)

Pored nesumnjivog uticaja na glikoregulaciju, lekovi iz ove grupe ostvaruju i značajan uticaj na telesnu masu. Pojedini preparati za terapiju DM (insulin, preparati sulfonil-uree i glitazoni) povezani su sa porastom telesne mase, ali je njihovo propisivanje (pioglitazon, glimepirid) sa dapagliflozinom praćeno redukcijom telesne mase. $(31,32,33)$ U ranim fazama terapije to je posledica gubitka tečnosti, a kasniji gubitak telesne mase posledica je kalorijskog gubitka (prosečno 200-300 kCal dnevno), što rezultira i gubitkom telesnih masti, kako potkožnog masnog tkiva tako i visceralnog, što je verifikovano i upotrebom sofisticiranih tehnika MRI (engl. magnetic resonance imaging, MRI). $(34,35)$ Bailey i saradnici su zabeležili gubitak $1.5-2.1 \mathrm{~kg}$ kod pacijenata koji se lečeni dapagliflozinom $10 \mathrm{mg}$ nakon neuspeha terapije metforminom, sa ili bez preparata sulfoniluree ili insulina tokom 24 nedelje trajanja strudije. Slični rezultati su postignuti i u drugim istraživanjima. $(36,37)$ Telesna masa se stabilizuje nakon 24 nedelje. $(36,38)$ Veći gubitak telesne mase je kod pacijenata koji su lečeni duže od 6 meseci. (38) McGovern je pokazao da je veći startni indeks telesne mase povezan sa većim gubitkom kilograma. (39) Gubitak telesne mase povezan sa upotrebom SGLT2 inhibitora održava se tokom kliničkih studija do 104 nedelje. (35)

Insulinska rezistencija (IR) i hipertenzija često koegzistiraju. Kliničke studije pokazuju da $50 \%$ osoba sa hipertenzijom ima IR ili neki od poremećaja glikoregulacije, dok čak $80 \%$ osoba sa DM2 ima hipertenziju. Efekat dapagliflozina na arterijski krvni pritisak ispitivan je kod obolelih od DM sa i bez arterijske hipertenzije. U dobro kontrolisanim studijama prosečna redukcija sistolnog i dijastolnog krvnog pritiska bila je 3,6 i 1,2 mmHg kod hipertenzivnih, a 2,6 i 1,2 mmHg kod normotenzivnih, bez promena u srčanoj frekvenci uz blagi porast proporcije pacijenata (oko $2 \%$ ) sa epizodama ortostatske hipotenzije kod osoba koje su koristile dapagliflozin kao placebo. (40) Mehanizmi kojima se objašnjava redukcija krvnog pritiska su: osmotska diureza, blaga natriureza, redukcija telesne mase, povećanje oslobađanja azot-monoksida - kao odgovor na smanjenje oksidativnog stresa usled poboljšanja glikoregulacije. $(41,42)$

Cilj moderne terapije DM2, pored uspostavljanja adekvatne glikoregulacije, smanjenje kardiovaskularnog rizika. Sprovedene su brojne studije koje su ispitivale mesto SGLT2 inhibitora u ovom procesu. EMPA-REG OUTCOME® studija iz 2015. god. pokazala je značajnu redukciju kardiovaskularnog mortaliteta i morbiditeta upotrebom ove klase lekova, a čekajući 2019. godinu i rezultate DECLARE-TIMI 58® studije (engl. Dapagliflozin Effect on CardiovascuLAR Events, DECLARE-TIMI 
58) koja ispituje uticaj dapagliflozina. Tokom 2017. godine objavljeni su rezultati velike svetske kliničke studije CVD-REAL (engl. Comparative Effectiveness of Cardiovascular Outcomes in New Users of SGLT-2 Inhibitors, CVD-REAL) koja je obuhvatila više od 300.000 pacijenata sa novootkrivenim DM2. Zaključak ove, ali i CVD-REAL Nordic studije jeste da je u populaciji pacijenata sa tipom 2 šećerne bolesti i visokim rizikom za kardiovaskularne bolesti upotreba ovih lekova povezana sa redukcijom i mortaliteta i morbiditeta od kardiovaskularnih oboljenja. $(43,44)$ To su osnovni razlozi zbog kojih su i ADA i EASD (engl. European association for the study of diabetes, EASD) izdale preporuke da se lekovi ove grupe koriste kao druga terapijska linija, nakon primarnog neuspeha metformina, posebno kod osoba sa rizikom za kardiovaskularna oboljenja. (45)

Mesto dejstva dapagliflozina je i mesto ispoljavanja još jednog značajnog efekta dapagliflozina, a to je nefroprotekcija. Indirektno renoprotektivno dejstvo se ostvaruje smanjenjem bubrežne resorpcije glukoze i smanjenjem koncentracije glukoze u krvi, uz redukciju telesne mase i indeksa telesne mase. Promenom bubrežne hemodinamike redukuje se intraglomerularni pritisak i smanjuje renalnu hiperfiltraciju i tubularnu hipertrofija, uz smanjenje direktnog toksičnog delovanja glukoze na tubule. $(46,47)$ Pokazano je smanjenje renalne hiperfiltracije, markera dijabetesne nefropatije, već nakon osmonedeljnog praćenja normotenzivnih ispitanika obolelih od DM tipa 1 koji su koristili SGLT2 inhibitor, empagliflozin u dozi od $25 \mathrm{mg}$. (48) Pretpostavlja se da su pozitivni efekti rezultat smanjenja resorpcije $\mathrm{Na}+$ zbog SGLT2 inhibicije, što izaziva tubuloglomerularni feedback (preko povećane isporuke natrijuma do macule densa i lokalnog povećanja angiotenzina II), aferentne vazokonstrikcije, smanjenja pritiska u glomerulu i reverzibilnog smanjenja glomerularne filtracije (GFR) svakog pojedinačnog nefrona. $(47,49)$ Navodi se i uticaj redukcije arterijskog pritiska uz smanjenje arterijskog "stiffness"-a, smanjenje vaskularnog otpora, pad serumske koncetracije mokraćne kiseline i smanjenje albuminurije, bez poremećaja nivoa kalijuma i modulacije neurohormonalnih odgovora, kao potencijalnih faktora koji doprinose nefroprotekciji. $(47,50) \mathrm{Na}$ kraju treba napomenuti da povećanje diureze može izazvati povećanje hematokrita i time bolju tubulointersticijalnu oksigenaciju i povećanje proizvodnje eritropoetina od strane fibroblasta. (47) Postoji prolazno povećanje urinarne eliminacije mokraćne kiseline uz smanjenje njene serumske koncentracije. (51)

\section{Klinička sigurnost dapagliflozina}

Adekvatnim izborom pacijenata stepen neželjenih efekata ove terapije može biti sveden na minimum. Oboleli od DM2 imaju povećan rizik od asimptomatske bakteriurije, infekcija urinarnog trakta, kao i genitalnih infekcija. (52) Povećanje tog rizika je veće kod osoba ženskog pola. Istraživanja ukazuju da faktori poput 
glukozurije olakšavaju rast bakterija i adherencu bakterija za epitel urotrakta, što povećava rizik od infekcija. (52) Upotreba lekova, kao što su SGLT2 inhibitori, koji indukuju glukozuriju olakšavaju razvoj genitalnih infekcija. Ova neželjena dejstva mogu se prevenirati adekvatnom perinealnom higijenom i antifungalnom terapijom.

Genitalne infekcije su najčešća nuspojava dapagliflozina. Infekcije su blage ili umerene, a do njih dolazi u prvih 6 meseci terapije sa niskim rizikom od recidiva ili relapsa infekcije sa potrebom za produženom terapijom. (53) Pacijenti sa pozitivnom anamnezom o ranijim genitalnim infekcijama imaju veći rizik od nove infekcije. Infekcije imaju dobar odgovor na standardnu antibiotsku terapiju i uglavnom nije bilo potreba za isključivanjem dapagliflozina iz terapije. (51) Infekcije urinarnog trakta su ređe i uglavnom blage, reaguju na uobičajenu antibiotsku terapiju. (53) Iako je rizik od razvoja ozbiljnih infekcija (pijelonefritisa i urosepse) mali, veći je nego kod osoba koje su primale placebo. (23)

Povećanje diureze za 350-450 $\mathrm{ml}$ ne prouzrokuje nokturiju. (54) Povećanje diureze može da uslovi tranzitorno povećanje serumske koncentracije kreatinina i uree.

Osmotska diureza povezana sa SGLT2 inhibitorima može biti potencionalni uzrok deplecije volumena i ortostatske hipotenzije, ali u dobro kontrolisanim studijama ovi efekti su bili minimalni $(<3 \%)$. (53)

Mehanizam delovanja SGLT2 inhibitora sugeriše mogućnost uticaja na koštanu gustinu preko promena u koncentracijama kalcijuma i fosfata. Zabeleženo je da SGLT2i uslovljavaju porast serumske koncentracije fosfata (uglavnom zbog povećane tubularne resorpcije) i PTH (engl. parathyroid hormone, PTH) uz istovremeno smanjenje koncentracije vitamina D. (53) Sveukupno, to bi moglo dovesti do smanjenog formiranja kosti i povećanja markera koštane razgradnje. Ranije mišljenje da je veći rizik od preloma kod pacijenata na terapiji sa dapagliflozinom nisu potvrdile skorašnje metaanalize (30384 pacijenata); rizik od fraktura bio je identičan za sve SGLT2i, naročito kod bolesnika sa GFR of $<45 \mathrm{ml} / \mathrm{min} / 1.73 \mathrm{~m} 2$. (25)

Rizik od hipoglikemija postoji ukoliko se ovi lekovi propisuju uz insulin ili preparate sulfoniluree, ali retko dovode do isključenja ovog leka iz terapije. (19)

U studijama sa dapagliflozinom kod $0.17 \%$ pacijenata prijavljen je karcinom mokraćne bešike prema $0,03 \%$ onih koji su primali placebo, s tim što su se mnogi od slučajeva javili u toku prve godine terapije sa dapagliflozinom, što smanjuje verovatnoću da je karcinom bio u vezi sa izlaganjem ovom leku. Bilo je četiri slučaja karcionoma mokraćne bešike kod pacijenata koji primaju dapagliflozin duže od godinu dana. Iako je broj slučajeva mali, dapagliflozin ne treba koristiti kod pacijenata sa aktivnim karcinomom mokraćne bešike i treba ga propisati oprezno kod osoba sa istorijom karcinoma mokraćne bešike i nerazjašnjenom hematurijom. (19) Pretpostavljeni mehanizam dejstva je da visoka koncentracija glukoze pojačava rast premalignih ćelija. (55) 
Dijabetična ketoacidoza (engl. diabetic ketoacidosis, DKA), koja je češća kod obolelih od DM1, ali se viđa i kod obolelih od DM2, može biti fatalna. FAERS (FDA Adverse Event Reporting System -FAERS) identifikovala je 73 slučaja sa euglikemijskom ketoacidozom u periodu mart 2013 - maj 2015, te je FDA izdala upozorenje o opasnosti od dijabetične ketoacidoze tokom upotrebe SGLT2i. Euglikemijska ketoacidoza se definiše kao dijabetesna ketoacidoza bez hiperglikemije. Potencijalni okidači su infekcija, smanjen kalorijski unos, upotreba alkohola, redukcija doza insulina. (55) Registrovani su slučajevi kod obolelih od oba tipa DM. Svim pacijenti sa DKA bio je potreban trajan prekid upotrebe dapagliflozina uz korekciju doze insulina i povećan unos ugljenih hidrata. $(56,57,58)$

\section{Zакljučaк}

Dapagliflozin, lek iz grupe SGLT2 inhibitora, efikasan je u redukciji HbA1C, u monoterapiji ili u kombinaciji sa drugim lekovima. Takođe je povezan sa blagom redukcijom telesne mase i arterijskog krvnog pritiska. S obzirom na dobru toleranciju leka, lako doziranje i minimalni rizik od neželjenih efekata, osim genitourinarnih infekcija, dapagliffozin, kao i drugi lekovi iz ove grupe adekvatan su izbor kod pacijenata obolelih od DM2, posebno onih sa visokim kardiovaskularnim rizikom.

\section{Reference:}

1. Đukić A, Đurđević P, Živančević-Simonović S, Jurišić V, Mijatović Lj. Opšta patološka fiziologija. Beograd; Intergraf: 2002; 400-408.

2. International Diabetes Federation. IDF Diabetes Atlas, 7th ed. International Diabetes Federation: Brussels, Belgium: 2015; available at: http://www.diabetesatlas.org

3. Stark Casagrande, S., Fradkin, J., Saydah, S., Rust, K. and Cowie, C. (2013) The prevalence of meeting A1C, blood pressure, and LDL goals among people with diabetes, 1988-2010. Diabetes Care 36: 2271-2279.

4. DeFronzo RA, Ferrannini E, Simonson DC. Fasting hypergly-cemia in non-insulin dependent diabetes mellitus: contributions of excessive hepatic glucose production and impaired tissue glucose uptake. Metabolism: 1989; 38: 387-395.

5. Jameson L. 3rd edition Harrison's endocrinology. McGraw-Hill Education: 2013; 251-307.

6. Larsen R, Kronenberg H. et ad. Williams textbook of endocrinology 12th edition. Elsevier Saunders: 2011; 1386-1436.

7. Jameson L. 3rd edition Harrison's endocrinology. McGraw-Hill Education: 2013; 251-307.

8. Bays HE, Gonzalez-Campoy JM, Bray GA, Kitabchi AE, Bergman DA, et al. Pathogenic potential of adipose tissue and metabolic consequences of adipocyte hypertrophy and increased visceral adiposity. Expert Rev Cardio Ther: 2008;6: 343-368. 
9. Bays H, Mandarino L, DeFronzo RA. Role of the adipocytes, FFA, and ectopic fat in the pathogenesis of type 2 diabetes mellitus: PPAR agonists provide a rational therapeutic approach. J Clin Endocrinol Metab: 2004; 89: 463-478.

10. Unger RH, Aguilar-Parada E, Muller WA, Eisentraut AM: Studies of pancreatic alpha cell function in normal and diabetic subjects. J Clin Invest. 1970; 49: 837-848.

11. Gerich JE. Role of the kidney in normal glucose homeostasis and in the hyperglycaemia of diabetes mellitus: therapeutic implications. Diabet Med: 2010; 27: 136-142.

12. Wright EM, Loo DD, Hirayama BA. Biology of human sodium glucose transporters. Physiol Rev 2011; 91: 733-94.

13. Brown GK. Glucose transporters: structure, function and consequences of deficiency. J Inherit Metab Dis: 2000; 23: 237-246.

14. Wright EM. Renal Na(+)-glucose cotransporters. Am J Physiol Renal Physiol: 2001; 280: $10-18$.

15. Andrianesis V, Glykofridi S, Doupis J. Therapeutic The renal effects of SGLT2 inhibitors and a mini-review of the literature. Ther Adv Endocrinol Metab: 2016; 7(5-6); 212-228.

16. Guyton, A. and Hall, J. Textbook of Medical Physiology 11th ed. Elsevier Saunders: Philadelphia, Pennsylvania: 2006; 327-347.

17. Wolf S, Rave K, Heinemann L, et al. Renal glucose excretion and tubular reabsorption rate related to blood glucose in subjects with type 2 diabetes with a critical reappraisal of the "renal glucose threshold" model. Horm Metab Res: 2009; 41.

18. Devineni D, Morrow L, Hompesch M, et al. Canagliflozin improves glycemic control over 28 days in subjects with type 2 diabetes not optimally controlled on insulin. Diabetes Obes Metab: 2012; 14: 539-45.

19. Bristol-Myers Squibb and AstraZeneca. Farxiga ${ }^{\circledR}$ (dapagliflozin). Full prescribing information. Princeton, NJ, and Wilmington, 2014.

20. Kilov G. Leow S. Thomas M. SGLT2 inhibition with dapagliflozin- A novel approach for the management of type 2 diabetes. Australian family physician: 2013; (42:10), 706-710.

21. Wright EM, Loo DD, Hirayama BA. Biology of human sodium glucose transporters. Physiol Rev 2011; 91: 733-94.

22. Anderson SL, Marrs JC. Dapagliflozin for the treatment of type 2 diabetes. Ann Pharmacother. 2012;46(4): 590-598.

23. Bailey C, Gross J, Hennicken D, Iqbal N., Mansfield T., List J. Dapagliflozin add-on to metformin in type 2 diabetes inadequately controlled with metformin: a randomized, double-blind, placebo-controlled 102-week trial. BMC Med: 2013; 11: 43.

24. Hinnen D. Glucuretic effects and renal safety of dapagliflozin in patients with type 2 diabetes. Ther Adv Endocrinol Metab: 2015;(6:3): 92-102.

25. Nauck MA. Update on developments with SGLT2 inhibitors in the management of type 2 diabetes. Drug Des Devel Ther: 2014; 8: 1335-1380.

26. Kalra S, Ghosh S, Aamir AH, et al. Safe and pragmatic use of sodium-glucose co-transporter 2 inhibitors in type 2 diabetes mellitus: South Asian Federation of Endocrine Societies consensus statement. Indian Journal of Endocrinology and Metabolism. 2017; (21;1): 210-230. 
27. Anderson SL. Dapagliflozin efficacy and safety: a perspective review. Ther Adv Drug Saf. 2014; (5:6): 242-254.

28. Ferrannini E, Ramos SJ, Salsali A, Tang W, List JF. Dapagliflozin monotherapy in type 2 diabetic patients with inadequate glycemic control by diet and exercise: a randomized, double-blind, placebo-controlled, phase 3 trial. Diabetes Care. 2010;33(10): 2217-2224.

29. Bailey C, Iqbal N, T'joen C. List J. Dapagliflozin monotherapy in drug-naïve patients with diabetes: a randomized-controlled trial of lowdose range. Diabetes Obes Metab: 2012; (14): 951-959.

30. List J, Woo V, Morales E, Tang W, Fiedorek F. Sodium-Glucose Cotransport Inhibition With Dapagliflozin in Type 2 Diabetes. DIABETES CARE, 2009;(32; 4).

31. UKPDS Group. Intensive blood-glucose control with sulphonylureas or insulin compared with conventional treatment and risk of complications in patients with type 2 diabetes (UKPDS 33). UK Prospective Diabetes Study (UKPDS) Group. Lancet. 1998; 352: 837-53.

32. UK Prospective Diabetes Study (UKPDS) Group. Intensive blood-glucose control with sulphonylureas or insulin compared with conventional treatment and risk of complications in patients with type 2 diabetes (UKPDS 33). Lancet:1998; 352: 837-53.

33. Rosenstock J., Vico M., Wei L., Salsali A., List J. Effects of dapagliflozin, an SGLT2 inhibitor, on $\mathrm{HbA}(1 \mathrm{c})$, body weight, and hypoglycemia risk in patients with type 2 diabetes inadequately controlled on pioglitazone monotherapy. Diabetes Care:2012; (35): $1473-1478$.

34. Bolinder J, Ljunggren Ö, Kullberg J, Johansson L, Wilding J, Langkilde AM, Sugg J. Parikh S. Effects of Dapagliflozin on Body Weight, Total Fat Mass, and Regional Adipose Tissue Distribution in Patients with Type 2 Diabetes Mellitus with Inadequate Glycemic Control on Metformin. J Clin Endocrinol Metab: 2012; (97:3): 1020-1031.

35. Bolinder J, Ljunggren O, Johansson L, et al. Dapagliflozin maintains glycaemic control while reducing weight and body fat mass over 2 years in patients with type 2 diabetes mellitus inadequately controlled on metformin. Diabetes Obes Metab: 2014; (16:2): 159-169.

36. Bailey C, Gross J, Pieters A, Bastien A, List J. Effect of dapagliflozin in patients with type 2 diabetes who have inadequate glycaemic control with metformin: a randomised, double-blind,placebo-controlled trial. Lancet. 2010; 375: 2223-2233.

37. Matthaei S, Bowering K, Rohwedder K, Grohl A, Parikh S, Study 05 Group. Dapagliflozin improves glycemic control and reduces body weight as add-on therapy to metformin plus sulfonylurea: a 24-week randomized, double-blind clinical trial. Diabetes Care. 2015; 38: 365-372.

38. Wilding JPH, Woo V, Soler NG, et al. Long-term efficacy of dapagliflozin in patients with type 2 diabetes mellitus receiving high doses of insulin: a randomized trial. Ann Intern Med. 2012; 156: 405-415.

39. McGovern A, Dutta N, Munro N, Watters K, Feher M. Dapagliflozin: clinical practice compared with pre-registration trial data. Br J Diabetes Vasc Dis: 2014; 14: 138-43.

40. Sjöström CD, Johansson P, Agata Ptaszynska A, List J, Johnsson E. Dapagliflozin lowers blood pressure in hypertensive and non-hypertensive patients with type 2 diabetes. Diabetes \& Vascular Disease Research: 2015; (12:5): 352-358. 
41. Majewski C, Bakris G. Blood Pressure Reduction: An Added Benefit of Sodium-Glucose Cotransporter 2 Inhibitors in Patients With Type 2 Diabetes. Diabetes Care: 2015, 38(3): 429-430.

42. Townsend RR, Machin I, Ren J, et al. Reductions in mean 24-hour ambulatory blood pressure after 6-week treatment with canagliflozin in patients with type 2 diabetes mellitus and hypertension. J Clin Hypertens (Greenwich) 2016; 18(1): 43-52.

43. The CVD-REAL Study: Lower Rates of Hospitalization for Heart Failure in New Users of SGLT-2 Inhibitors Versus Other Glucose Lowering Drugs - Real-World Data From Four Countries and More Than 360,000 Patients; presented 19 March at ACC 2017.

44. KI Birkeland, ME Jørgensen, В Carstensen ет ад:Cardiovascular mortality and morbidity in patients with type 2 diabetes following initiation of sodium-glucose co-transporter-2 inhibitors versus other glucose-lowering drugs (CVD-REAL Nordic): a multinational observational analysis. The Lancet Diabetes \& Endocrinology: (5; 9); 2017, 709-71.

45. American Diabetes Association. Standards of Medical Care in Diabetes. Diabetes Care; 2017: (40;1).

46. De Nicola L, Gabbai FB, Liberti ME, Sagliocca A, Conte G, Minutolo R. Sodium/glucose cotransporter 2 inhibitors and prevention of diabetic nephropathy: targeting the renal tubule in diabetes. Am J Kidney Dis. 2014; 64:16-24.

47. Zou H, Zhou B, Xu G. SGLT2 inhibitors: a novel choice for the combination therapy in diabetic kidney disease. Cardiovascular Diabetology: 2017; (16:1); Page 1.

48. Cherney DZ, Perkins BA, Soleymanlou N, et al. Renal hemodynamic effect of sodium-glucose cotransporter 2 inhibition in patients with type 1 diabetes mellitus. Circulation: 2014; 129: 587-97.

49. Škrtić M, Cherney DZ. Sodium-glucose cotransporter-2 inhibition and the potential for renal protection in diabetic nephropathy. Curr Opin Nephrol Hypertens: 2015; 24: 96-103.

50. Trujillo JM, Jennifer M., Wesley A. Nuffer. Impact of Sodium-Glucose Cotransporter 2 Inhibitors on Nonglycemic Outcomes in Patients with Type 2 Diabetes. Pharmacotherapy: 2017; (37.4): 481-491.

51. Saeed M, Narendran P. Dapagliflozin for the treatment of type 2 diabetes: a review of the literature . Drug Design, Development and Therapy: 2014; 8: 2493-250.

52. Benfield T, Jensen JS, Nordestgaard BG. Influence of diabetes and hyperglycaemia on infectious disease hospitalisation and outcome. Diabetologia: 2007; (50:3): 549-54.

53. Johnsson KM, Ptaszynska A, Schmitz B, Sugg J, Parikh SJ, List JF. Urinary tract infections in patients with diabetes treated with dapagliflozin. J Diabetes Complications:. 2013; 27(5): 473-478.

54. Kalra S. Sodium Glucose Co-Transporter-2 (SGLT2) Inhibitors: A Review of Their Basic and Clinical Pharmacology. Diabetes Therapy. 2014;5(2):355-366.

55. Burki TK. FDA rejects novel diabetes drug over safety fears. Lancet. 2012 Feb 11; 379(9815): 507.

56. US Food and Drug Administration. FDA Drug Safety Communication: FDA revises labels of SGLT2 inhibitors for diabetes to include warnings about too much acid in the blood and serious urinary tract infections.. Issued 2018. 
57. Dandona P. Chaudhuri A. Sodium-glucose co-transporter 2 inhibitors for type 2 diabetes mellitus: An overview for the primary care physician. International Journal of Clinical Practice: 2017; (71-5).

58. Pujara S, Ioachimescu A. Prolonged Ketosis in a Patient With Euglycemic Diabetic Ketoacidosis Secondary to Dapagliflozin. Journal of Investigative Medicine High Impact Case Reports. 2017; 5(2). 